\title{
Sea surface wind perturbations over the Kashevarov Bank of the Okhotsk Sea: a satellite study
}

\author{
T. I. Tarkhova, M. S. Permyakov, E. Yu. Potalova, and V. I. Semykin \\ Department of Satellite Oceanology, Laboratory of the Ocean and Atmosphere Interaction Studies, V. I. Il'ichev Pacific \\ Oceanological Institute of the Far Eastern Branch of Russian Academy of Sciences, Vladivostok, Russia
}

Received: 21 September 2010 - Revised: 10 January 2011 - Accepted: 14 February 2011 - Published: 22 February 2011

\begin{abstract}
Sea surface wind perturbations over sea surface temperature (SST) cold anomalies over the Kashevarov Bank (KB) of the Okhotsk Sea are analyzed using satellite (AMSR-E and QuikSCAT) data during the summerautumn period of 2006-2009. It is shown, that frequency of cases of wind speed decreasing over a cold spot in AugustSeptember reaches up to $67 \%$. In the cold spot center SST cold anomalies reached $10.5^{\circ} \mathrm{C}$ and wind speed lowered down to $\sim 7 \mathrm{~m} \mathrm{~s}^{-1}$ relative its value on the periphery. The wind difference between a periphery and a centre of the cold spot is proportional to SST difference with the correlations 0.5 for daily satellite passes data, 0.66 for 3-day mean data and 0.9 for monthly ones. For all types of data the coefficient of proportionality consists of $\sim 0.3 \mathrm{~m} \mathrm{~s}^{-1}$ on $1{ }^{\circ} \mathrm{C}$.
\end{abstract}

Keywords. Meteorology and atmospheric dynamics (Ocean-atmosphere interactions) - Radio science (Remote sensing)

\section{Introduction}

It is widely known that the structure and intensity of the wind field perturbations are determined to a considerable extent by the underlying SST heterogeneity. Breeze circulation is a striking example of this influence. During last decades, due to the development of remote sensing technologies, a great number of works dealing with the influence of different structure formations in SST fields in the form of fronts in oceans and seas (e.g., Chelton et al., 2001; Vecchi et al., 2004; Samelson et al., 2006; Shimada and Kawamura, 2006), currents (e.g., Nonaka and Xie, 2003; Tokinaga et al., 2005; O'Neil et al., 2005; Song et al., 2006; Chelton et al., 2007),

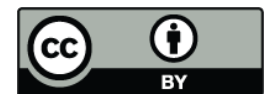

Correspondence to: T. I. Tarkhova (tit@poi.dvo.ru) rings (Park and Cornillon, 2002; Park et al., 2006) and disturbances in tropical cyclones "traces" (Lin et al., 2003) on the surface wind field and connected with it wind stress over the surface, its curl and divergence has been carried out. These and other works (reviews in Xie, 2004; Small et al., 2008) show that the wind perturbation magnitude is directly determined by the amplitude of SST contrasts in state formations. The coupling between wind and SST is expected to show most accurately in ocean and sea regions with anomalous high temperature contrasts. In this respect the Kashevarov Bank area in the north-western part of the Okhotsk Sea is of great interest.

The Kashevarov Bank is a bottom rising about $350-900 \mathrm{~m}$ comparatively to the surrounding relief. $200-\mathrm{m}$ isobath contouring the $\mathrm{KB}$ is limited to co-ordinates $55^{\circ} 12^{\prime} \mathrm{N}-55^{\circ} 57^{\prime} \mathrm{N}$ and $144^{\circ} 48^{\prime} \mathrm{E}-146^{\circ} 50^{\prime} \mathrm{E}$ (dotted line in Figs. 1 and 2). The minimum depth of the $\mathrm{KB}$ is $\sim 100 \mathrm{~m}$, the mean one is $\sim 180 \mathrm{~m}$. The characteristic feature of surface waters over the KB is the formation of a cold spot in summer, in which the SST over the KB is always a few degrees colder than the surrounding water. Hydrological sections carried out through the cold spot showed almost homogeneous thermohaline structure which is formed by strong tidal mixing (Rogachev et al., 2000). The maximum of phyto-, zooplankton and zoobenthos concentration over the KB are marked during a frost-free seasons, favouring the formation of food fish accumulation (Luchin, 1996). Thus, the KB has a substantial influence on the hydrological and biological processes in the Okhotsk Sea (Rogachev et al., 2001; Ono et al., 2006).

In the work (Tokinaga and Xie, 2009) while investigating the influence of the tidal cooling on the sea fog in the Okhotsk Sea, it was noted the wind decreasing in JulyAugust from $6 \mathrm{~m} \mathrm{~s}^{-1}$ down to $4 \mathrm{~m} \mathrm{~s}^{-1}$ across the cold spot over the KB. But the real variability range of SST and wind anomalies in this region is much wider. Thus, SST and wind data over the KB can be used for the development of empirical relationships between wind and SST anomalies, similarly

Published by Copernicus Publications on behalf of the European Geosciences Union. 

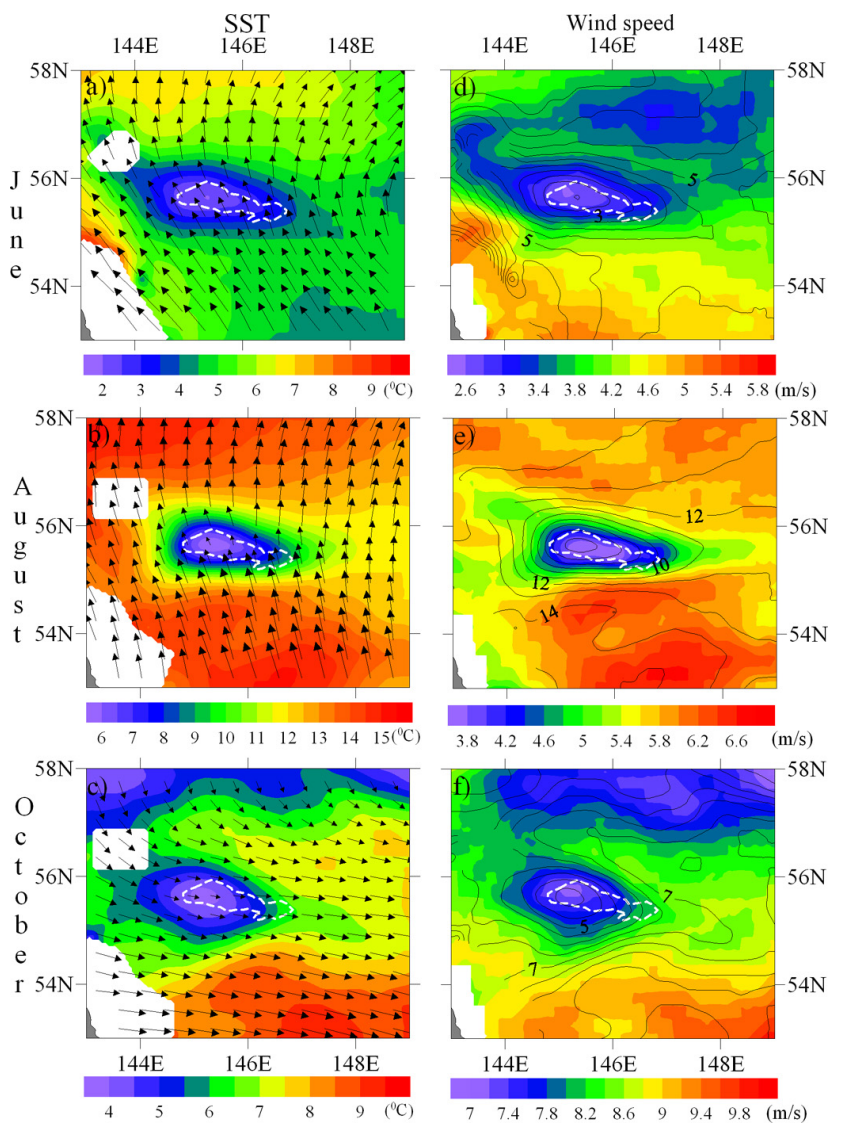

Fig. 1. Monthly average SST (a)-(c) and wind speed (d)-(f) fields during the summer-autumn period in 2006. White dotted line is isobath $200 \mathrm{~m}$.

to that how it was done for other regions of the World Ocean (Small et al., 2008). The purpose of the present paper is the investigation of the empirical relationships of SST and wind anomalies over the KB using satellite data.

\section{Data and methods}

In this work we have used vector wind and SST product of Remote Sensing Systems (RSS) (http://www.remss.com). Wind vectors have been derived from NASA's scatterometer SeaWinds onboard QuikSCAT and calibrated to the neutral stability wind at a height of $10 \mathrm{~m}$ over the sea surface, while SST fields have been obtained with an Advanced Microwave Scanning Radiometer for Earth Observing System (EOS) onboard Aqua (hereafter AMSR-E). In this work we use daily passes, 3-day and monthly average data of vector wind and SST with spatial resolution $0.25^{\circ}$ for the period of 20062009 in the region limited to the co-ordinates $53^{\circ} \mathrm{N}-58^{\circ} \mathrm{N}$ and $143^{\circ} \mathrm{E}-149^{\circ} \mathrm{E}$. The accuracies of scatterometer wind speed and direction estimations are $\sim 1.7 \mathrm{~m} \mathrm{~s}^{-1}$ and $\sim 14^{\circ}$, respectively (Chelton and Freilich, 2005). The accuracy of AMSR-E SST measurements is $0.4{ }^{\circ} \mathrm{C}$ (Chelton and Wentz,

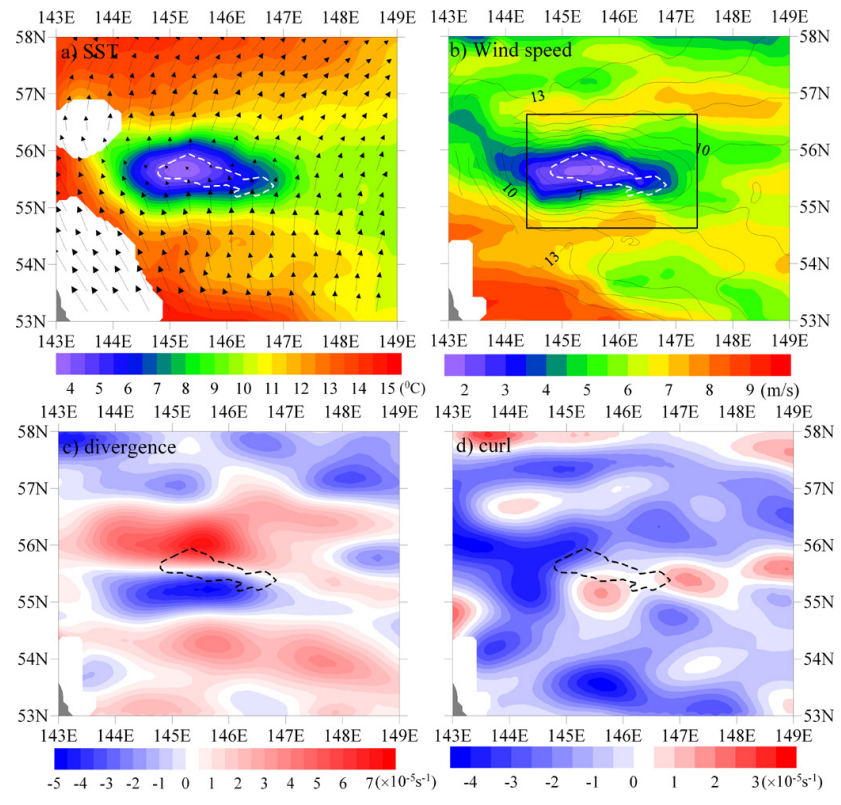

Fig. 2. Unfiltered fields of (a) AMSR-E SST with QuikSCAT wind vector, (b) QuikSCAT wind speed with isotherms, divergence (c) and curl (d) wind from descending satellite pass on 29 July 2006. The wind curl and divergence were calculated across the wind field, smoothed with the use of Gaussian filter with bandwidth $50 \mathrm{~km}$. A dotted line is isobath $200 \mathrm{~m}$.

2005). For comparative analysis we have enlisted Japanese 25-year ReAnalysis (JRA-25) products of the Japan Meteorological Agency (JMA) and the Central Research Institute of Electric Power Industry (CRIEPI) (http://jra.kishou.go.jp). These data are with spatial resolution $1.25^{\circ}$ and with a time slot in $6 \mathrm{~h}$.

For quantitative analysis of coupling of wind and SST anomalies we used data in the field of $250 \times 250 \mathrm{~km}$ and a centre $\left(55.5^{\circ} \mathrm{N}\right.$ and $\left.146^{\circ} \mathrm{E}\right)$ which is near to the $\mathrm{KB}$ centre. Anomaly grids are the grids in which deviations of values from background ones exceed some threshold value. Background grids are values of a two-dimensional polynomial regression function of the 3 order, formed due to the leastsquares method with a data selection. The data selection is an exception of grids with data differences from the regression exceeded two standard deviations. This procedure is done twice and leads to exceptions of a grid influence in a cold spot upon the smoothed SST field. All grids in which SST values are $1^{\circ} \mathrm{C}$ lower than regression values and are in the radius of $120 \mathrm{~km}$ from the $\mathrm{KB}$ centre, are considered to be the grids of a cold anomaly over the KB. The same procedure is carried out for marking out wind anomaly grids in which wind speed is $0.5 \mathrm{~m} \mathrm{~s}^{-1}$ lower than regression values. Periphery grids are chosen out of numerous initial data in a ring with an inward radius equal to the maximum point radius in a cold spot over the $\mathrm{KB}$, and in an angular sector $45^{\circ}$ with a course determined by the average wind direction (according 
to the whole selection). We suppose that, in general, SST and wind in such periphery grids determine the initial surface air characteristics spreading over the cold spot. Thus, SST and wind speed differences are the differences between their minimum values for SST and wind anomaly grids over the $\mathrm{KB}$ and mean magnitudes at the cold spot periphery. Wind speed ratio is the relation of wind speed minimum for wind anomaly grids to the mean speed of periphery grids.

\section{Results}

A cold spot over the KB begins to be forming as usual at the end of May-at the beginning of June with the appearance of water stratification outside its bound because of springsummer warming up and disappears in October-November when stratification is destroyed as a result of autumn-winter convection. In Fig. 1 monthly average SST fields (left panel) together with vector of sea surface wind and wind speed field with isotherms (right panel) are shown for June, August and October 2006. One can see that there is a positive correlation between wind speed and SST, and in monthly average wind speed fields over the cold spot a low speed region appears that closely resembles the cooler SST. For example, in June (Fig. 1a) and July (not shown) the field of colder SST covers a vast region, including, besides the $\mathrm{KB}$, the Iona Bank, located northward of Iona Island. Average SST for June in the chosen region was $4.8^{\circ} \mathrm{C}$ in the $\mathrm{KB}$ periphery with a minimum of $\sim 2{ }^{\circ} \mathrm{C}$ over the KB. Similarly, the southeast wind speed was $3.8 \mathrm{~m} \mathrm{~s}^{-1}$ on the SST spot periphery and $2.4 \mathrm{~m} \mathrm{~s}^{-1}$ over the KB (Fig. 1d). Maximum monthly wind speed $\left(5.2 \mathrm{~m} \mathrm{~s}^{-1}\right)$ may be noted over the most warmed up shelf water of North Sakhalin (up to $9^{\circ} \mathrm{C}$ ). In July (not shown) monthly SST in given region raised and kept itself in the range from the minimum $3.5^{\circ} \mathrm{C}$ over the $\mathrm{KB}$ up to $\sim 9.3^{\circ} \mathrm{C}$ at the cold spot periphery. Southeastern wind speed lowered over the cold spot from $\sim 5.2 \mathrm{~m} \mathrm{~s}^{-1}$ beyond their bounds down to $3.6 \mathrm{~m} \mathrm{~s}^{-1}$. Surface wind fields for both June and July, low speed fields marked as a closed isotach $3.4 \mathrm{~m} \mathrm{~s}^{-1}$ and $4.6 \mathrm{~m} \mathrm{~s}^{-1}$, correspondingly, coincide practically completely with cold spots.

In August temperature contrasts between the centre of the cold spot and its periphery become the maximum, from $5.5^{\circ} \mathrm{C}$ up to $13.7^{\circ} \mathrm{C}$ (Fig. 1b). And besides, south wind speed over the $\mathrm{KB}$ is lowering from $\sim 6 \mathrm{~m} \mathrm{~s}^{-1}$ down to $3.6 \mathrm{~m} \mathrm{~s}^{-1}$ (Fig. 1e). Then it is increasing up to $5.8-6 \mathrm{~m} \mathrm{~s}^{-1}$ beyond the KB. Thus, the SST difference $\sim 8.2^{\circ} \mathrm{C}$ corresponds to $\sim 2.4 \mathrm{~m} \mathrm{~s}^{-1}$ wind decreasing.

In autumn water stratification surrounding the $\mathrm{KB}$ begins to be destroyed due to cooling, which leads to gradual diminishing of thermal contrasts over the sea surface. In September (not shown) this process is not so noticeable, when monthly mean temperature of the cold spot periphery lowered down to $\sim 10^{\circ} \mathrm{C}$, and over the $\mathrm{KB}$ down to $\sim 5.4^{\circ} \mathrm{C}$. The SST difference between minimum over the KB and SST beyond it lowered down to $\sim 4.6^{\circ} \mathrm{C}$. Southwestward winds are predominant in this time. Wind speed was descending from $6.5 \mathrm{~m} \mathrm{~s}^{-1}$ down to $4.6 \mathrm{~m} \mathrm{~s}^{-1}$ over the KB. Thus, the temperature contrast $4.6^{\circ} \mathrm{C}$ corresponds to $1.9 \mathrm{~m} \mathrm{~s}^{-1}$ wind speed lowering. From October to April north and north-western winds are prevalent over the Okhotsk Sea. Despite the considerable diminishing of thermal contrasts in the KB region and sea surface wind intensification up to $10 \mathrm{~m} \mathrm{~s}^{-1}$, in October positive correlation between SST and wind speed is still observed. Monthly SST throughout the investigated region was changing from $\sim 5.1^{\circ} \mathrm{C}$ at the cold spot periphery down to $\sim 3.8^{\circ} \mathrm{C}$ over the $\mathrm{KB}$ (Fig. $1 \mathrm{c}$ ). At the same time the wind speed changed from $8 \mathrm{~m} \mathrm{~s}^{-1}$ to $7.2 \mathrm{~m} \mathrm{~s}^{-1}$ (Fig. 1f).

Correlation between SST and wind is not seen from November till May, the more so, as from the end of January up to the middle of May the investigated region is covered with ice and there is no practically data. During the summerautumn period of 2007-2009 (not shown) the coupling between SST and wind is qualitatively similar to that one in 2006.

The mentioned coupling between monthly SST and wind speed is evident in single satellite passes as well. As an example in Fig. 2 unfiltered fields AMSR-E SST and QuikSCAT surface wind from descending satellite passes on 29 July 2006, as well as divergence and curl calculated according from a smoothed wind field are shown. The minimum SST over the $\mathrm{KB}$ that day was about $3.6^{\circ} \mathrm{C}$, while beyond its bound SST reached $12^{\circ} \mathrm{C}$ and more (Fig. 2a). Over the cold spot wind speed was lowered from $\sim 7 \mathrm{~m} \mathrm{~s}^{-1}$ down to $1.5 \mathrm{~m} \mathrm{~s}^{-1}$ (Fig. 2b). Anomalous low wind speed area contoured with isotach $4 \mathrm{~m} \mathrm{~s}^{-1}$ and anomalous cold temperature region contoured with isotherm $8^{\circ} \mathrm{C}$ practically coincide. Wind direction over the cold spot veered by $7-13 \%$ relative to mean wind similar to wind veering over the cold rings of Gulf Stream (Park et al., 2006). The wind fields were compared with reanalysis JRA-25 data. That day there was no disturbance in reanalysis fields of sea level pressure and wind during the day. It is connected with a coarse spatial resolution of reanalysis data and spatial-time smoothing of JRA procedure itself.

In the fields of wind divergence (Fig. 2c) and curl (Fig. 2d) characteristic structures can be marked. In the divergence field over the cold spot two bands with positive and negative (convergence) values were formed which divide it into two nearly equal parts. Convergence reaches its maximum values $\left(-5 \times 10^{-5} \mathrm{~s}^{-1}\right)$ on the upwind side of the cold spot, whereas divergence on the downwind side is peak $\left(7 \times 10^{-5} \mathrm{~s}^{-1}\right)$. From the left side of the cold spot wind curl becomes of negative magnitude and reaches $-3.5 \times 10^{-5} \mathrm{~s}^{-1}$, while from the right side one its value is positive and does not exceed $1.5 \times 10^{-5} \mathrm{~s}^{-1}$. Quality similar patterns of wind stress divergence and curl fields have been received over cold rings of Gulf Stream (Park et al., 2006).

We estimated the correlation factors between SST and wind speed using the daily satellite passes during the ice-free 


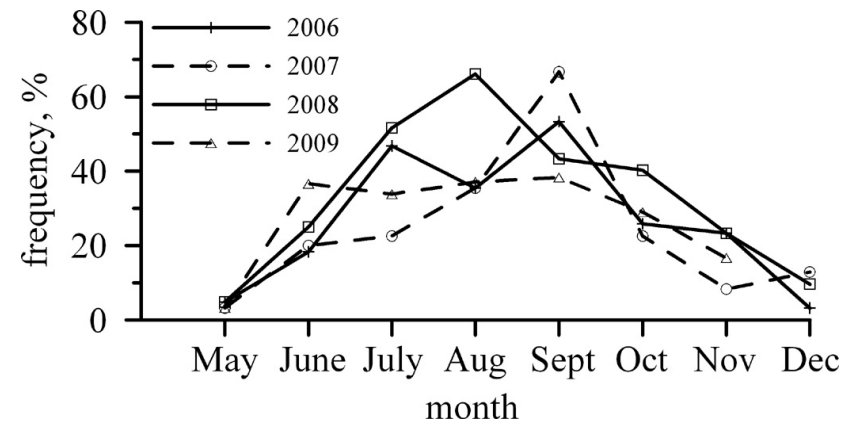

Fig. 3. Monthly frequency of cases with correlation between daily SST and wind speed more or equal 0.5 for May-December 20062009 in the area limited in co-ordinates $54^{\circ} 30^{\prime} \mathrm{N}-56^{\circ} 30^{\prime} \mathrm{N}$ and $144^{\circ} 15^{\prime} \mathrm{E}-147^{\circ} 15^{\prime} \mathrm{E}$.

period of 2006-2009 in the area limited in co-ordinates $54^{\circ} 30^{\prime} \mathrm{N}-56^{\circ} 30^{\prime} \mathrm{N}$ and $144^{\circ} 15^{\prime} \mathrm{E}-147^{\circ} 15^{\prime} \mathrm{E}$ (a black box on Fig. 2b). They were carried out only when the volume of data sample was more than $80 \%$ of the maximum possible $(9 \times 13$ grid). The highest correlation between SST and wind speed 0.94 was received for a descending pass on 29 July 2006 (Fig. 2). However, there were only four cases with such correlation $(\geq 0.9)$. The time course of monthly frequency of cases with correlation exceeding or equal 0.5 is shown in Fig. 3. Apparently from Fig. 3, it grows from a minimum in May (3-5\%) to a maximum in August-September (38-67\%), then again drops to $3-13 \%$ in November-December. For comparison, the frequency of advective sea fog occurrence connected with relatively warm air flowing over a colder spot surface over the $\mathrm{KB}$ and with wind decreasing exceeds $\sim 60 \%$ in July-August (Tokinaga and Xie, 2009).

Figure 4 presents the relationship between SST and wind anomalies for data of satellite passes, for 3-day mean and monthly data for June-October 2006-2009. For its analysis there were selected days when correlation in the area limited in co-ordinates $54^{\circ} 30^{\prime} \mathrm{N}-56^{\circ} 30^{\prime} \mathrm{N}$ and $144^{\circ} 15^{\prime} \mathrm{E}-147^{\circ} 15^{\prime} \mathrm{E}$ is larger or equal to 0.5 . Figure 4 in the left column shows the scatterplots of SST and wind speed differences, in the right column it presents the scatterplots of SST difference and wind speed ratio. For daily data (Fig. 4a and b) the correlation factor $(r)$ between SST and wind speed anomalies is $\sim 0.5$, the coupling becomes stronger with correlation up to 0.67 for 3-day average data and for monthly data it reaches its high values $\sim 0.9$. It is important to mark that linear regression slope is $\sim 0.3$ and $\sim 0.05$ for a wind speed difference and a wind speed ratio, respectively, and almost doesn't depend on a scale of averaging, which influences only on the range of data variability in Fig. 4.

Figure 4 shows wind speed decreasing when the air flowing over the cold spot reaches $\sim 7.3 \mathrm{~m} \mathrm{~s}^{-1}, 4.8 \mathrm{~m} \mathrm{~s}^{-1}$ and $3 \mathrm{~m} \mathrm{~s}^{-1}$ for daily, 3-day mean and monthly data, correspondingly. The SST anomalies reaches $10.5^{\circ} \mathrm{C}, 10.1^{\circ} \mathrm{C}, 8.2^{\circ} \mathrm{C}$, respectively.

\section{Discussion}

The results presented in Sect. 3 do not contradict similar ones received by other researchers in various areas of the World Ocean (Small et al., 2008). But the range of temperature and wind speed differences over the KB is wider. For example, according to satellite passes in a typhoon Kai-Tak "wake" they reached $7^{\circ} \mathrm{C}$ and $5.5 \mathrm{~m} \mathrm{~s}^{-1}$ (Lin et al., 2003), and in a typhoon Ioke "wake" $3.5^{\circ} \mathrm{C}$ and $3 \mathrm{~m} \mathrm{~s}^{-1}$ (Tarkhova et al., 2010). In Tokinaga and Xie (2009) climatological value of SST and wind differences were given in July-August with $7^{\circ} \mathrm{C}$ and $2 \mathrm{~m} \mathrm{~s}^{-1}$, accordingly. Besides, there was a negative correlation on the sub-monthly time scale. Nevertheless, as it is shown in Figs. 3 and 4, both in 3-day average data and even on daily passes, considerable correlation occurs with high frequency.

In Fig. 4a, c and e a regression line slope is $\sim 0.3 \mathrm{~m} \mathrm{~s}^{-1}$ on $1^{\circ} \mathrm{C}$. The same slope estimation has been derived for the coupling of wind and SST anomalies around the Japan Sea Polar front (Shimada and Kawamura, 2006) for the warm period of a year. According to data for five months 1999 (Hashizume et al., 2001) yields estimations of mean regression coefficient in the equatorial South (North) Pacific are $1.83(0.64) \mathrm{ms}^{-1} \mathrm{~K}^{-1}$. Such high values of difference ratios over the KB were marked only in some days. For example, value 0.85 around the $\mathrm{KB}$ was received due to a single satellite pass on 29 June 2006 (Fig. 2).

In Park and Cornillon (2002), Park et al. (2006) it is shown, that over warm (cold) rings of Gulf Stream wind speed increases (decreases) by 10-15\%. Horizontal dimensions of cold rings appear comparable with the size of a cold spot over the KB, SST difference magnitudes $\left(4-8^{\circ} \mathrm{C}\right)$ in them are comparable as well. Figure 4 shows the same monotonous character of dependence "wind speed ratio/SST difference", as in Fig. 3 from (Park and Cornillon, 2002) and in Fig. 11 from Park et al. (2006). Our results do not contradict from the point of view of monotony and a variability range to theoretical dependence in The University of Washington Planetary Boundary Layer (UWPBL) model (Foster and Brown, 1994), used for calculations in work (Park et al., 2006), but our data give a wider range of variability (almost in 2 times) for wind speed ratio and SST difference.

The influence of SST heterogeneity on wind may be interpreted in the terms of a baroclinic atmosphere boundary layer theory (Brown and Liu, 1982; Bannon and Salem, 1995; Park et al., 2006). A substantial observation of physical mechanisms of sea surface wind and SST heterogeneity coupling is given in the paper (Small et al., 2008). We can mark the most frequently mentioned ones among them. The first is the influence of a SST-induced modification of the sea surface air stability (Wallace et al., 1989; Samelson et al., 2006). It was used by Tokinaga and Xie (2009) for explaining of the influence of SST anomalies on the wind over the KB. The second is SST-induced sea level pressure variation (Lindzen and Nigam, 1987; Small et al., 2005). As a rule, in a planetary 

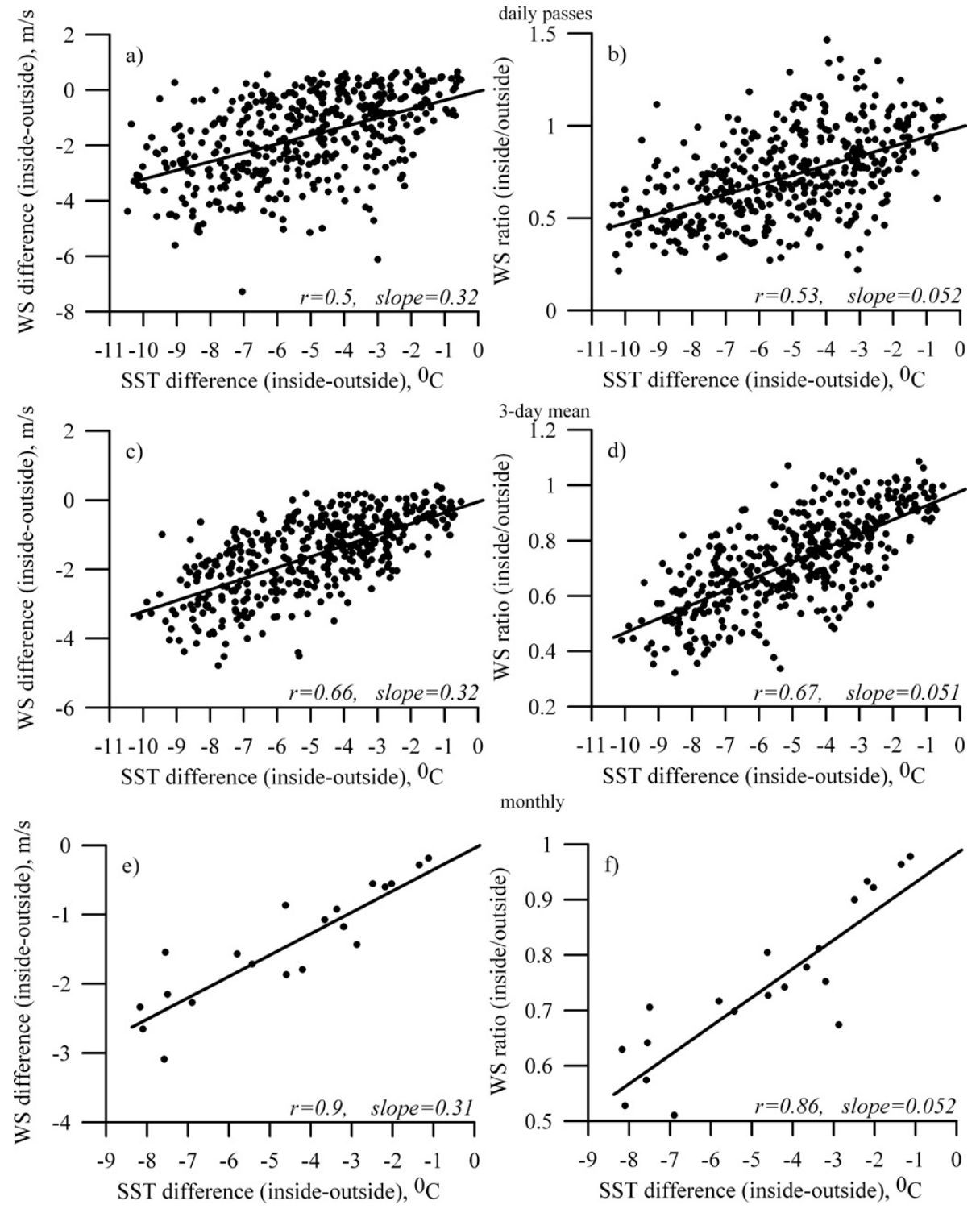

Fig. 4. Scatterplots of wind speed (WS) and SST difference (left panel) and wind speed ratio and SST difference (right panel) according to daily passes (top), 3-day average (centre) and monthly average (bottom) data for June-October 2006-2009.

boundary layer (PBL) model similar to UWPBL model (Foster and Brown, 1994) both mechanisms are taken into consideration. But, the contribution of each of these mechanisms to sea surface wind variability over the KB should be investigated in future.

As we investigate the empirical relationships of wind and SST anomalies, it is necessary to note a number of factors which can influence on wind estimations by a scatterometer. Firstly, the scatterometer signal depends on a surface condition, but to a considerable extent, upon capillary level and short gravity waves and is defined by transfer momentum processes from the wind to sea surface (Brown, 2000). The scatterometer-derived wind is considered to be relative to sea surface and not taking into account current speed brings to er- ror in its magnitude (Kelly et al., 2001) and a direction (Park et al., 2006). Around the KB tidal current speeds can reach $1.64 \mathrm{~m} \mathrm{~s}^{-1}$ (Rogachev et al., 2000), that can cause rather big errors in wind estimation by scatterometer during summerautumn period with typical for its light winds. Such tidal currents and the KB topography result in intensive eddies on a surface which cannot be considered in wind evaluating procedures and which also can result in to significant errors.

Secondly, the considerable errors at small winds can be also connected with the fact that "... ripple formation on a pure surface occurs at wind speed $1.5-3 \mathrm{~m} \mathrm{~s}^{-1}$, but in the presence of a surfactant species film" the wind speed being necessary for waves generation increases (Phillips, 1977). The occurrence of such a film can be caused by 
high bioproductivity of the KB area, and results to clearing of small-scale surface waves and surface smoothing as well (Hühnerfuss et al., 1978), and as consequence, to understating of wind speed estimations. Besides, growth rate and dissipation of a roughness are defined by water viscosity (Phillips, 1977) depending on temperature, and which can increase on more than by $15 \%$ at decrease SST on $5^{\circ} \mathrm{C}$ in a range of SST from 0 to $15^{\circ} \mathrm{C}$ over the KB. Such effects of temperature dependence of air and water viscosity are not considered in the empirical ratio, connecting a scatterometer signal and sea surface wind (Brown, 2000; Park et al., 2006).

Thirdly, errors in wind estimations can be a result of assumption about the neutral stratification of a surface atmosphere layer in empirical relationships of the scatterometer signal and wind (Brown, 2000). The stratification of a surface atmosphere layer defined in basic water-air temperature difference is not considered. It is practically impossible to measure this difference neither by radiometers nor by scatterometers. In our case it is possible to assume strong stability of sea surface air over a cold spot with a difference between water and air temperatures to $-10.5^{\circ} \mathrm{C}$ (if it needs to be estimated as in Park et al. (2006), on the SST difference on periphery and in the cold spot centre) and nearby $-7.5^{\circ} \mathrm{C}$ (if to use air temperature reanalysis data for Fig. 2). Such high stability results in decreasing of small-scale perturbation or flaw which participate in generation of a small-scale roughness component (Phillips, 1977), so it can yield decrease in a scatterometer wind concerning the real one.

Influence estimation of above mentioned factors on the scatterometer wind needs undersatellite direct measurements of water and air temperatures in the KB area and it will be the theme of a future investigation.

\section{Conclusion}

The main aim of the present work was the investigation of empirical relationships of SST and wind anomalies over the Kashevarov Bank in the Okhotsk Sea according to satellite data. SST anomalies during summer-autumn seasons reach $\sim 10.5^{\circ} \mathrm{C}$ and wind speed $\sim 7 \mathrm{~m} \mathrm{~s}^{-1}$. Case frequencies with the correlation between SST and wind speed fields more than 0.5 mount to their maximum up to $67 \%$ in AugustSeptember during an annual course. The wind difference between a periphery and a centre of cold spot is proportional to SST difference with a slope $\sim 0.3 \mathrm{~m} \mathrm{~s}^{-1}$ on $1^{\circ} \mathrm{C}$, which practically doesn't depend on a period of averaged data, with a correlation of SST and wind differences between a periphery and a centre of cold spot from 0.5 according to daily satellite passes data up to 0.9 for monthly average data.

Acknowledgements. The authors thank two anonymous reviewers for their important remarks, comments and constructive recommendations. The QuikScat and AMSR-E data are produced by Remote Sensing Systems and sponsored by the NASA Ocean Vector Winds Science Team, the NASA Earth Science MEaSUREs DISCOVER
Project and the AMSR-E Science Team. The JRA-25 data were obtained from Web site of the Japan Meteorological Agency. This research has been supported by a grant from Far Eastern Branch of Russian Academy of Sciences (no. 09-III-A-07-333) and partially by a grant from Russian Foundation For Basic Research (no. 09-0500640).

Topical Editor P. Drobinski thanks two anonymous referees for their help in evaluating this paper.

\section{References}

Bannon, P. R. and Salem, T. L.: Aspects of the baroclinic boundary layer, J. Atmos. Sci., 52, 574-596, 1995.

Brown, R. A.: On satellite scatterometer model functions, J. Geophys. Res., 105(D23), 29195-29205, 2000.

Brown, R. A. and Liu, W. T.: An operational large-scale marine planetary boundary layer model, J. Appl. Meteor., 21, 261-269, 1982.

Chelton, D. B. and Freilich, M. H.: Scatterometer-based assessment of 10-m wind analyses from the operational ECMWF and NCEP numerical weather prediction models, Mon. Weather Rev., 133, 409-429, 2005.

Chelton, D. B. and Wentz, F. J.: Global microwave satellite observations of sea surface temperature for numerical weather prediction and climate research, B. Am. Meteorol. Soc., 86(8), 1097-1115, 2005.

Chelton, D. B., Esbensen, S. K., Schlax, M. G., Thum, N., Freilich, M. H., Wentz, F. J., Gentemann, C. L., McPhaden, M. J., and Schopf, P. S.: Observations of coupling between surface wind stress and sea surface temperature in the eastern tropical Pacific, J. Climate, 14, 1479-1498, 2001.

Chelton, D. B., Schlax, M. G., and Samelson, R. M.: Summertime coupling between sea surface temperature and wind stress in the California current system, J. Phys. Oceanogr., 37, 495517, 2007.

Foster, R. C. and Brown, R. A.: On large-scale PBL modeling: Surface Layer Models, Glob. Atmos. Ocean Sys., 2, 185-198, 1994.

Hashizume, H., Xie, S.-P., Liu, W. T., and Takeuchi, K.: Local and remote atmospheric response to tropical instability waves: A global view from the space, J. Geophys. Res., 106(D10), 1017310185, 2001.

Hühnerfuss, H., Alpers, W., and Jones, W. L.: Measurements at 13.9 GHz of radar backscattering cross section of the North Sea covered with an artificial surface film, Radio Sci., 13(6), 979983, 1978.

Kelly, K. A., Dickinson, S., McPhaden, M. J., and Johnson, G. C.: Ocean currents evident in satellite wind data, Geophys. Res. Lett., 28(12), 2469-2472, 2001.

Lin, I. I., Liu, W. T., Wu, C. C., Chiang, J. C. H., and Sui, C. H.: Satellite observations of modulation of surface winds by typhoon-induced upper ocean cooling, Geophys. Res. Lett., 30(3), 1131, doi:10.1029/2002GL015674, 2003.

Lindzen, R. S. and Nigam, S.: On the role of sea-surface temperature gradients in forcing low-level winds and convergence in the tropics, J. Atmos. Sci., 44(17), 2418-2436, 1987.

Luchin, V. A.: Water masses in the Okhotsk Sea, PICES Scientific Report, 6, 81-88, 1996.

Nonaka, M. and Xie, S. P.: Covariations of sea surface temperature and wind over the Kuroshio and its extension: evidence for 
ocean-to-atmosphere feedback, J. Climate, 16, 1404-1413, 2003. O'Neill, L. W., Chelton, D. B., Esbensen, S. K., and Wentz, F. J.: High-resolution satellite measurements of the atmospheric boundary layer response to SST variations along the Agulhas Return current, J. Climate, 18, 2706-2723, 2005.

Ono, J., Ohshima, K. I., Mizuta, G., Fukamachi, Y., and Wakatsuchi, M.: Amplification of diurnal tides over Kashevarov Bank in the Sea of Okhotsk and its impact on water mixing and sea ice, Deep-Sea Res. I, 53, 409-424, 2006.

Park, K. A. and Cornillon, P. C.: Stability-induced modification of sea surface wind over Gulf Stream rings, Geophys. Res. Lett., 29(24), 2211, doi:10.1029/2001GL014236, 2002.

Park, K. A., Cornillon, P. C., and Codiga, D. L.: Modification of surface wind near ocean fronts: effects of Gulf Stream rings on scatterometer (QuikSCAT, NSCAT) wind observations, J. Geophys. Res., 111, C03021, doi:10.1029/2005JC003016, 2006.

Phillips, O. M.: The Dynamics of the Upper Ocean, 2nd ed., Cambridge Univ. Press, New York, 1977.

Rogachev, K. A., Carmack, E. C., and Salomatin, A. S.: Strong tidal mixing and ventilation of cold intermediate water at Kashevarov Bank, Sea of Okhotsk, J. Oceanogr., 56(4), 439-447, 2000.

Rogachev, K. A., Carmack, E. C., Salomatin, A. S., and Alexanina, M. G.: Lunar fortnightly modulation of tidal mixing near Kashevarov Bank, Sea of Okhotsk, and its impacts on biota and sea ice, Prog. Oceanogr., 49, 373-390, 2001.

Samelson, R. M., Skyllingstad, E. D., Chelton, D. B., Esbensen, S. K., O'Neill, L. W., and Thum, N.: On the coupling of wind stress and sea surface temperature, J. Climate, 19, 1557-1566, 2006.

Shimada, T. and Kawamura, H.: Satellite observations of sea surface temperature and sea surface wind coupling in the Japan Sea, J. Geophys. Res., 111, C08010, doi:10.1029/2005JC003345, 2006.
Small, R. J., Xie, S. P., and Hafner, J.: Satellite observations of mesoscale ocean features and copropagating atmospheric surface fields in the tropical belt, J. Geophys. Res., 110, C02021, doi:10.1029/2004JC002598, 2005.

Small, R. J., deSzoeke, S. P., Xie, S. P., O’Neill, L., Seo, H., Song, Q., Cornillon, P., Spall, M., and Minobe, S.: Air-sea interaction over ocean fronts and eddies, Dyn. Atmos. Ocean, 45, 274-319, 2008.

Song, Q., Cornillon, P., and Hara, T.: Surface wind response to oceanic fronts, J. Geophys. Res., 111, C12006, doi:10.1029/2006JC003680, 2006.

Tarkhova, T. I., Permyakov, M. S., Potalova, E. Y., and Semykin, V. I.: About the coupling of surface wind anomalies and sea surface temperature gradients according to remote sensing data, Current problems in remote sensing of Earth from Space, 7(3), 45-52, 2010 (in Russian).

Tokinaga, H. and Xie, S. P.: Ocean tidal cooling effect on summer sea fog over the Okhotsk, J. Geophys. Res., 114, D14102, doi:10.1029/2008JD011477, 2009.

Tokinaga, H., Tanimoto, Y., and Xie, S.-P.: SST-induced surface wind variations over the Brazil-Malvinas Confluence: satellite and in situ observations, J. Climate, 18, 3470-3482, 2005.

Vecchi, G. A., Xie, S. P., and Fischer, A. S.: Ocean-atmosphere covariability in the western Arabian Sea, J. Climate, 17, 12131224, 2004.

Wallace, J. M., Mitchell, T. P., and Deser, C.: The influence of sea-surface temperature on surface wind in the eastern equatorial Pacific: seasonal and interannual variability, J. Climate, 2, 14921499, 1989.

Xie, S. P.: Satellite observations of cool ocean-atmosphere interaction, B. Am. Meteorol. Soc., 85, 195-208, 2004. 